\title{
4G to 5G Network Evolution: Advantages and Differences
}

\author{
Samir Čaušević, Adisa Medić \\ Faculty of Traffic and Communications, University of Sarajevo, Sarajevo, Bosnia and Herzegovina
}

\begin{abstract}
Starting from the emergence of $1^{\text {st }}$ Generation network (1G), wireless mobile communications have been undergoing an evolution from $2^{\text {nd }}$ Generation (2G), $3^{\text {rd }}$ Generation (3G), $4^{\text {th }}$ Generation (4G) networks to $5^{\text {th }}$ Generation network (5G) at present. The fifth era is only a continuation of the ongoing evolution as it is still in the research phase and is also the basis for further development of industries and the society in general.

The paper presents and compares the fourth and fifth generation of wireless mobile communications, focusing on the differences and progress in terms of data transmission rate, capacity, architecture, technology and applied multiple-technique approaches and services provided.
\end{abstract}

Keywords - 4G and 5G, network demands, architecture, multiple-technique approaches, Handoff.

\section{Introduction}

With the aim of meeting the growing demands and needs of both users and service providers, mobile communication systems have recently been constantly developing and advancing. Hence, the generations of mobile technologies, i.e., $1 \mathrm{G}, 2 \mathrm{G}, 3 \mathrm{G}$, and $4 \mathrm{G}$, have been experiencing different upgrades compatible with new telecommunications standards.

DOI: $10.18421 /$ SAR44-01

https://doi.org/10.18421/SAR44-01

Corresponding author: Adisa Medić, Faculty of Traffic and Communications, University of Sarajevo, Sarajevo, Bosnia and Herzegovina.

Email: $\underline{\text { sadisa@hotmail.com }}$

Received: 08 August 2021.

Revised: 24 November 2021.

Accepted: 01 December 2021.

Published: 27 December 2021.

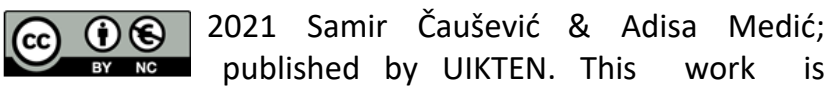
licensed under the CC BY-NC 4.0.

The article is published with Open Access at www.sarjournal.com
Each generation comprises its own unique characteristics and features; therefore, mobile operators more and more successfully keep meeting the required demands and offering a better-quality service to users.

$4 \mathrm{G}$ stands for the fourth generation of the mobile network that offers a broadband mobile access to great speeds of data and is a direct successor of $3 \mathrm{G}$ ( $3^{\text {rd }}$ Generation) mobile technologies network. In addition to the advantages, it offers in comparison to 3G (a greater speed of data transmission, better quality of service), $5 \mathrm{G}$ is a step forward that provides the user with more choices and acts as a basis for further digital development.

$5 \mathrm{G}$ is being developed as the new wireless standard of ultra-fast broadband network and is an upgrade of the existing generations -4G (LTE), 3G (UMTS) and $2 \mathrm{G}$ (GSM). Since the $5 \mathrm{G}$ era is approaching in terms of electronic devices and with the aim of gaining a better insight into what changes the $5 \mathrm{G}$ network is going to introduce in comparison to the previous generation, in the lines that follow, the present paper defines the key advantages and differences in comparison to $4 \mathrm{G}$.

\section{Network Demands in the 4G-to-5G Evolution}

The $3^{\text {rd }}$ Generation Partnership Project has developed and presented to the public the new LTE technology (Long Term Evolution) which is the basis for 4G. After the first workshop held in 2004 on the topic of the improvement of the $3 \mathrm{G}$ system, in the period that followed, different research-oriented activities were conducted and specifications were defined for the new LTE telecommunications standard, which was first implemented in 2009 in Norway and Sweden. [1] 4G systems comprise another standard besides LTE technology called WIMAX (Worldwide Interoperability for Microwave Access) which allows a mobile and fixed internet access [2]. WIMAX was implemented in South Korea for the first time in 2007 and in 2008, it was implemented in the USA. "LTE $10^{\text {th }}$ Edition", also referred to as "LTE Advanced", presents a significant step in the development of $4 \mathrm{G}$ [3] and a great improvement of the LTE mobile standard. 
With the aim of defining $5 \mathrm{G}$ differences in comparison to the $4 \mathrm{G}$ network, it is of utmost importance to point to the way and rate of their implementation: LTE network is undergoing a relatively fast implementation whereas the development of the 5G network is still based on research and pilot projects. [4]
The implementation of the $5 \mathrm{G}$ network was expected to occur in 2020 [5] and it also brought demands which are, together with the requirements defined by the $4 \mathrm{G}$ network, presented in the Table 1 for comparison:

Table 1. A comparative review of defined $4 G$ and $5 G$ requirements

\section{LTE, LTE-ADVANCED REQUIREMENTS: [6],[7]}

- data transmission speed (downlink -1Gbit/s, uplink - $500 \mathrm{Mbit} / \mathrm{s}$ ),

- reduced delay and latency under $10 \mathrm{~ms}$,

- bandwidth: downlink -70 MHz, uplink - $40 \mathrm{MHz}$,

- simplified architecture; core network built on the IP protocol,

- efficient usage of the spectrum available

- reducing power in terminals,

- LTE-A: In comparison to LTE, the data transmission speed is two times faster at cell-edge and the average data transmission speed per user is three times faster,

- advanced management and processing of the multimedia traffic and mobility.

\section{G REQUIREMENTS: [8], [9]}

- data transmission speed is ten times faster in comparison to LTE: from 1 to $10 \mathrm{Gbps}$ in real networks,

- reduced delay of $1 \mathrm{~ms}$,

- great bandwidth of devices within a small area,

- connectivity among thousands of devices is ensured,

- possibility of establishing connection while moving at the speed of up to $500 \mathrm{~km} / \mathrm{h}$,

- $100 \%$ coverage regardless of the user's location,

- enhanced energy efficiency and development of green technologies,

- longer battery life-span.

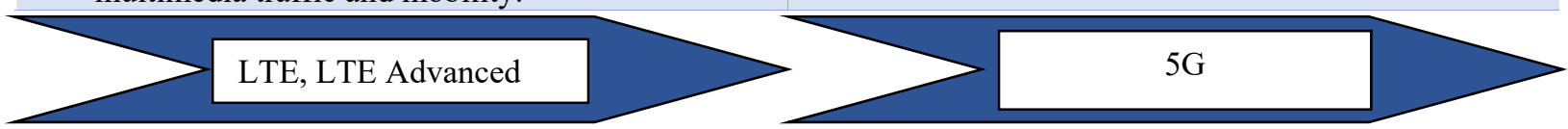

The technological development of the 5G network has introduced differences and advantages in comparison to the previous generation not only in terms of the way and rate of implementation but also when it comes to the speed of data transmission, capacity, latency, reliability and coverage.

In discussions about 4G and 5G networks, speed is often a specification used for the key difference between $4 \mathrm{G}$ and $5 \mathrm{G}$ networks which makes sense, taking into consideration the fact that each new generation introduces improvement in this sense. When it comes to the $4 \mathrm{G}$ network, the data speed ranges from $2 \mathrm{Mbps}$ to $1 \mathrm{Gbps}$, while it is expected that the $5 \mathrm{G}$ network will provide the speed of $1 \mathrm{Gbps}$ or more, if and when necessary. [5] The authors [10] consider that the greatest challenges posed for the $5 \mathrm{G}$ network are those pertaining to the massive increase of connected devices, all starting with low latency. Aside from the data transmission speed, latency, as a unit of measurement for the time the package needs from the starting to the final point, and it is considered to be the key difference between the $4 \mathrm{G}$ and 5G standard. [11], [12] At the moment, it amounts to 50 milliseconds in $4 \mathrm{G}$ networks, while it is expected that in the case of the $5 \mathrm{G}$ network, it will be reduced to an impressive amount of time - $1 \mathrm{~ms}$.

In comparison to $4 \mathrm{G}$, the $5 \mathrm{G}$ network, as an emerging wireless broadband network, will provide the solution for the problem of congestion due to a great number of devices in relatively small areas (e.g., sports halls, concert halls, airports, etc.) due to its far greater bandwidth/capacity. One of the reasons for providing a greater capacity is a more efficient usage of the frequency spectrum. In the next part of the paper, differences between $4 \mathrm{G}$ and $5 \mathrm{G}$ will be discussed in terms of architecture, applied technologies and services provided.

\section{Bases and Architecture of $4 \mathrm{G}$ and $5 \mathrm{G}$ Networks}

In order to reach the parameters set as characteristic for the $4 \mathrm{G}$ network, the LTE standard offers an innovation of the network architecture comprising two basic parts (shown in Figure 1) [13], [14]:

An evolved radio access network (E-UTRAN) which is made up of the eNodeB networks as the main elements in charge of managing distribution of radio resources and the implementation of adaptable modulation and coding;

An Evolved Packet Core (EPC) whose function comprises authentication and allocation of security keys and also allows access to outside data networks. MME (Mobility Management Entity), S-GW (Serving Gateway), P-GW (Packet Data Network Gateway), HSS (Home Subscriber Server) and PCRF (Policy Control and Charging Rules Function) are the 
components that comprise the core of the network completely based on the IP protocol.

Each of the components offers certain functionalities. For instance, the MME component is in charge of control by means of offering network access and registration; S-GW and P-GW allocate IP addresses; HSS presents the database, and PCRF provides a certain service to the user, depending on the user package.

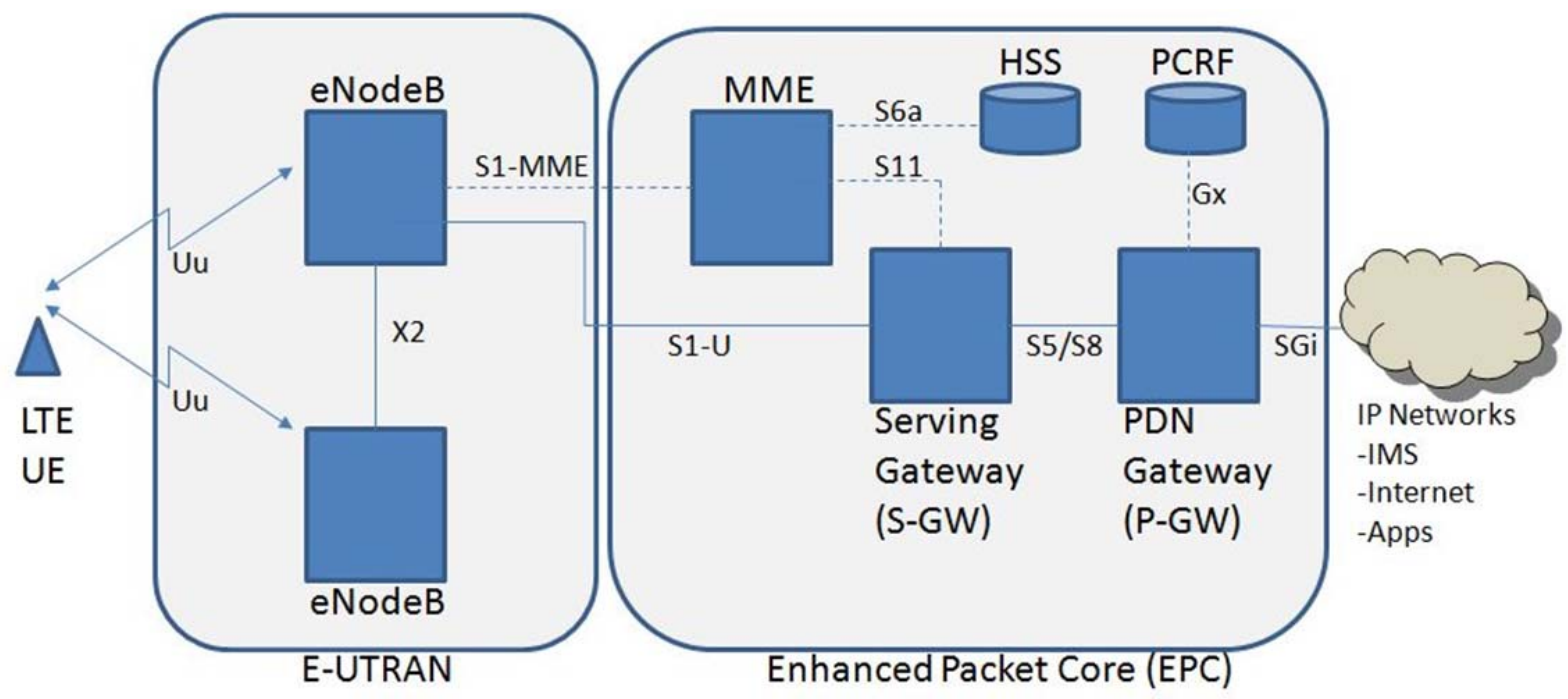

Figure 1. LTE architecture [15]

If we observe the core of the LTE network from another perspective, we can notice that it comprises the transport network as the real interconnection network, a layer of inter-equipment composed of both the hardware and the software layer and implementation on the providers and the application layer. [7]

In comparison to the $4 \mathrm{G}$ architecture, $5 \mathrm{G}$ architecture is completely changed and is cloudbased [16].
A new radio access and core part of the network has been developed and the very implementation implies connections between different technologies (see Figure 2) such as SDN (Software Defined Network), NFV (Network Functions Virtualisation), MEC (Mobile Edge Cloud) [17], a massive MIMO (Multiple Input Multiple Output), CRN (Cognitive Radio Network) and other technologies that will be mentioned in the paper.

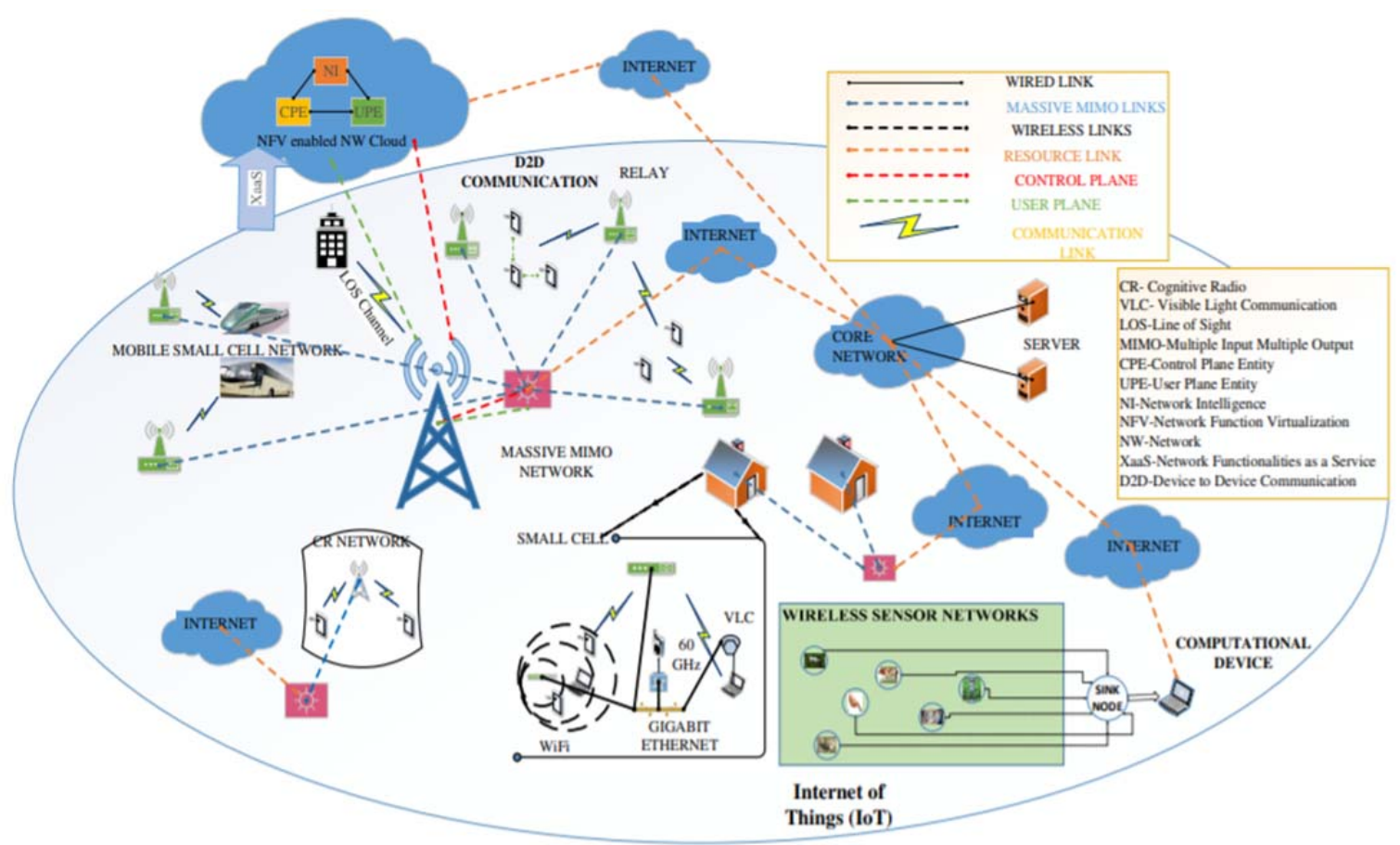

Figure 2. A representation of $5 G$ cellular architecture [18] 


\subsection{New Technologies of $5 G$ network}

The implementation of $5 \mathrm{G}$ introduces new technologies that are emerging for the first time and, hence, significantly affect the way mobile networks are perceived. Potential technologies that will be characteristic for the $5 \mathrm{G}$ standard are listed below:

Millimetre Wave Communication. A successful $5 \mathrm{G}$ wireless communication will imply a usage of an earlier used frequency spectrum in combination with the free frequency spectrum of higher frequencies and an allocation of a new frequency spectrum that will meet all the requirements posed for $5 \mathrm{G}$. The aim is to research unused millimetre waves in the high frequency bandwidth, the range of which is up to 300GHz. The millimetre waves technology brings numerous advantages in terms of reaching great data transmission speeds and great amounts of data. On the other hand, they are sensitive to weather changes, they are of low range [19], and the penetration losses are greater as well as losses in transmission. Therefore, the range of millimetre waves has to use the cells of the radius limited to $100 \mathrm{~m}$ in order to reduce weaknesses in signal propagation. This is also in compliance with the idea of densely distributed small cells.

Ultra-Dense Network. In order to maintain perfect coverage and minimal interference, 5G mobile networks architecture has to be heterogenous, i.e., varied and with a great number of densely distributed cells. Furthermore, the cells are classified based on the range they cover as follows: macrocells (range from $1-35 \mathrm{~km}$ ), microcells (range $2 \mathrm{~km}$ ), picocells (range 200 metres) and femtocells (range from 10 to 20 metres) [20].

Beamforming and massive MIMO. Method of multi-layered transmissions, or where a multiple input-multiple output implies more antennae-based solutions with base stations and terminal devices. By means of a great number of antennae on the base stations positioned in such a way as to achieve an efficient data-delivery route, it is possible to achieve a great spectral and energy-efficient solution [21] as well as to provide service to a great number of users within the same frequency spectrum. [22] Beamforming technology is based on the concept of directed signal in which case the signal from the emitter to the receiver is delivered along a precisely defined route. The signal reaches the user intact, and potential interruptions are reducing-related [23].

Network Functions Virtualisation (NFV). Network Functions Virtualisation is a concept of network architecture in which the traditional hardware network functions (such as signal directioning and firewalls) are being replaced by computers whose software provides the same functionality. The network functions are created by means of software solutions. They are performed on virtual devices and can be activated in the cloud from any part of the network. [24], [6].

Software Defined Networking (SDN). A technology that, by means of centralising network resources and dividing the control from the data layer, allows a software-based network management. A centralisation of network intelligence to SDN controllers allows numerous advantages such as control of the whole network from one spot, a more simplified operating of network devices [25], while, on the other hand, it can affect the controller to act as a bottleneck for the whole network due to network attacks. [26]

Machine-to-Machine (M2M) communication. $\mathrm{M} 2 \mathrm{M}$ communication refers to the connection and information exchange between two or more devices, with a minimal or no human interaction. It is maintained using wired/wireless technologies, and it provides solutions for automation in the industry, transport, logistics and resource management [27], as well as for automation in cities and systems for health management [28]. In energetics, M2M technology provides potential services such as smart metres, as well as services in telemetrics, public transport, navigation, vehicle tracking, ATMs, vending machines, and etc.

Device-to-Device (D2D). In mobile networks, D2D communication is defined as a direct link between two proximal mobile users without involvement of the base station, i.e., without involvement of the network infrastructure. It has found its application in the 5G network in local services, such as advertisements by shopping centres, cinemas, etc. or in cases of natural disasters and for the improvement of IoT (e.g. vehicle-to-vehicle communication) [29]. The main goal of this technology is to increase performance of the network in terms of energy consumption, spectrum efficiency and bandwidth [30].

Internet of Things (IoT). IoT is a technology of connecting physical devices, vehicles and other, which collect, distribute and exchange data by means of the Internet. M2M and IoT are very similar technologies and sometimes one can be mistaken for the other. Therefore, in the lines that follow, we point to their essential differences: M2M was developed earlier and is the base of IoT. It uses wired/wireless communication and enables devices to communicate and perform necessary actions without human intervention. IoT technology uses wireless communication and connects smart devices with the network for the collection of data, analysis and making smart decisions. Furthermore, IoT relies heavily on the Internet connectivity, the cloud, etc., whereas M2M mainly relies on the wired network. It is important to mention that M2M with the Internet 
protocol is a part of IoT. IoT is a broader term than $\mathrm{M} 2 \mathrm{M}$ as it can be integrated in an all-encompassing company business solution while $\mathrm{M} 2 \mathrm{M}$ is more maintenance-oriented. IoT also changes the way everyday activities are performed; it changes processes and activities in different industries applying the concepts of smart homes, cities, industries, agriculture and autonomous vehicles [31].

\section{Techniques of Multiple Access in 4G and 5G Wireless Communication}

In mobile communications, multiple access is a multi-user version of multiplexing which allows multiple users to send and receive data by means of one frequency carrier.

As the $5 \mathrm{G}$ network is expected to support different requests of users and thus allow for a connectivity among a great number of devices, new modulation techniques are essential in comparison to those from earlier generations, as well as increasing the width of the frequency belt in the millimetre wave belt ranging from 3 to $300 \mathrm{GHz}$ [32]. Multiple access techniques are used with the aim of having a greater number of users share the spectrum available and in a most efficient way. During the evolution of wireless communications, modulation techniques were changing as well. Therefore, the Code Division Multiple Access (CDMA) technique of $3 \mathrm{G}$ was changed to Orthogonal Frequency Division Multiple Access (OFDMA) technique for the 4G network, and OFDMA technique was replaced by NOMA (NonOrthogonal Multiple Access) technique for the $5 \mathrm{G}$ network.

OFDMA is a modulation technique in the downlink of the LTE network with the division of the frequency belt into more and smaller subsets where each subset has their orthogonal subcarriers. In the uplink, SC-FDMA is applied (Single Carrier Frequency Division Multiple Access).

NOMA, as a new multiple access technique of the 5G network, allows multiple users to simultaneously utilise the same resource, time and frequency.

It seeks to find out the possibilities of OFDM systems compatibility. It is expected that it will provide a high spectral efficiency, distribute transmission power to weak users, and provide support for a great number of connected devices, flexibility, low latency and compatibility. [33], [34].

\section{Handoff in $4 G$ and $5 G$ network}

Handoff refers to the way mobile connection is transmitted from one node to another when the node previously used can no longer provide the service requested. The horizontal Handoff scheme ensures quality in wireless mobile technologies and it is, therefore, insisted that this scheme is be used as it causes almost no losses in data, which is one of the key requirements of the most recent generation users. Since mobile devices are used in different areas, both urban and rural, and due to the fact that $5 \mathrm{G}$ cannot cover all areas, it is believed that, in the future period, $4 \mathrm{G}$ and $5 \mathrm{G}$ will work together and complement each other.

Handoff between $4 \mathrm{G}$ and $5 \mathrm{G}$ is illustrated below. Figure 3 shows that Handoff occurs frequently and the working modes are being changed, which is why mobile devices frequently switch from one mode to another - from $4 \mathrm{G}$ to $5 \mathrm{G}$ (Figure 3; marked in red) and from 5G to 4G (Figure 3; marked in black). Once selected, the working mode will last for approximately 10 seconds before the switch to another working mode.

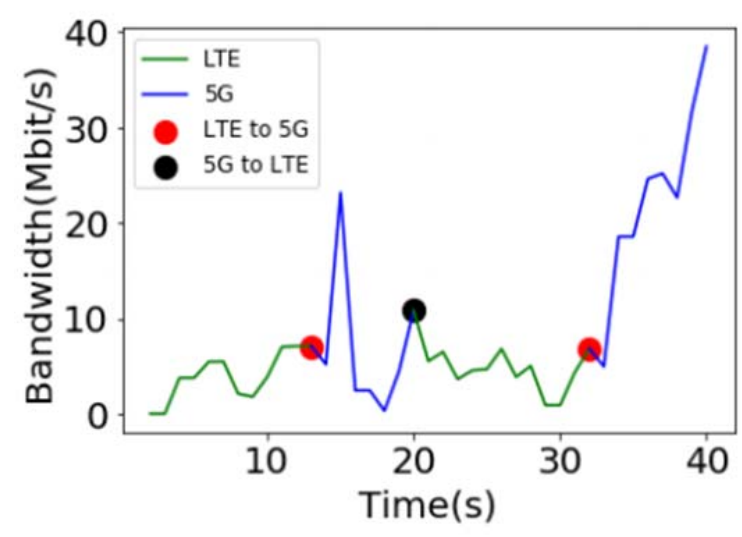

Figure 3. Handoff working mode in LTE/5G network [35]

The aim of Handoffs is to provide the working mode that will ensure the least number of losses (smaller than $10^{6}$ ) in the given moment of transmission and, at the same time, meet QoS user requirements.

\section{Conclusion}

We are witnessing that needs and demands of users are increasing on a daily basis and that changes in mobile telecommunications networks generations occur approximately every ten years. The challenges the $4 \mathrm{G}$ network is facing, such as a significant increase of data traffic, requests for new services, connectedness of a great number of devices, great speeds of data transmission, very insignificant delays and great bandwidth, can be overcome and new solutions implemented only by means of improving the existing and development of new technologies provided by the fifth generation of mobile networks.

In order to achieve the above-stated requirements, and provide support for new business models, the 5G network architecture will drastically change by means of an implementation of high-density cells, $\mathrm{mm}$ waves development, allocating new space to the 
frequency spectrum, using Beamforming and MIMO technology, software-defined networking and virtualisation of network functions.

mobile telecommunication. IEEE communications magazine, 52(5), 36-43.

New multiple access techniques will also be prevalent, as well as new technological concepts, such as D2D, M2M and IoT, which will allow the 5G network to play an important role in our lives as it will provide completely new possibilities and services.

Automation in industry, transport and logistics, resource management, public utilities and health care systems are only some of the segments in which the $5 \mathrm{G}$ network will bring revolutionary changes into the business sector. Even though $5 \mathrm{G}$ started being implemented in only several countries that launched the $5 \mathrm{G}$ infrastructure in big cities, a lot of time is required for the experience of the $5 \mathrm{G}$ network full potential and for all its advantages mentioned in this paper to be fully utilised.

\section{References}

[1]. Fundak, D. (2016). $5 G$ mobilni komunikacijski sustavi (Doctoral dissertation, Josip Juraj Strossmayer University of Osijek. Faculty of Electrical Engineering, Computer Science and Information Technology Osijek. Department of Communications. Chair of Radiocommunications and Telecommunications).

[2]. Kumar, A., Liu, Y., \& Sengupta, J. (2010). Evolution of mobile wireless communication networks $1 \mathrm{G}$ to 4G. International Journal of electronics \& communication technology, 1(1), 68-72.

[3]. Diel, P., Schnake, K. J., Langheinrich, A., \& Kandziora, F. (2014). Dislocation of double-threaded screws after stabilization of the odontoid process with the Knöringer technique. Der Unfallchirurg, 117(2), 179-181.

[4]. Gopal, B. G., \& Kuppusamy, P. G. (2015). A comparative study on $4 \mathrm{G}$ and $5 \mathrm{G}$ technology for wireless applications. IOSR Journal of Electronics and Communication Engineering, 10(6), 2278-2834.

[5]. Hajlaoui, E., Zaier, A., Khlifi, A., Ghodhbane, J., Hamed, M. B., \& Sbita, L. (2020, September). 4G and 5G technologies: A Comparative Study. In 2020 5th International Conference on Advanced Technologies for Signal and Image Processing (ATSIP) (pp. 1-6). IEEE.

[6]. Burazer, B. (2014). Budućnost mobilnih komunikacija i izazovi normizacije. Hrvatski zavod za norme.

[7]. Sule, P., \& Joshi, A. (2014). Architectural shift from $4 \mathrm{G}$ to $5 \mathrm{G}$ wireless mobile networks. International Journal of Computer Science and Mobile Computing, 3(9), 715-721.

[8]. Andrews, J. G., Buzzi, S., Choi, W., Hanly, S. V., Lozano, A., Soong, A. C., \& Zhang, J. C. (2014). What will $5 \mathrm{G}$ be?. IEEE Journal on selected areas in communications, 32(6), 1065-1082.
[9]. Chen, S., \& Zhao, J. (2014). The requirements, challenges, and technologies for $5 \mathrm{G}$ of terrestrial mobile telecommunication. IEEE communications magazine, 52(5), 36-43.

[10]. Osseiran, A., Boccardi, F., Braun, V., Kusume, K., Marsch, P., Maternia, M., ... \& Fallgren, M. (2014). Scenarios for $5 \mathrm{G}$ mobile and wireless communications: the vision of the METIS project. IEEE communications magazine, 52(5), 2635.

[11]. Jungnickel, V., Manolakis, K., Zirwas, W., Panzner, B., Braun, V., Lossow, M., ... \& Svensson, T. (2014). The role of small cells, coordinated multipoint, and massive MIMO in 5G. IEEE communications magazine, 52(5), 44-51.

[12]. Calabuig, D., Barmpounakis, S., Gimenez, S., Kousaridas, A., Lakshmana, T. R., Lorca, J., ... \& Maternia, M. (2017). Resource and mobility management in the network layer of 5G cellular ultradense networks. IEEE Communications Magazine, 55(6), 162-169.

[13]. Gavrić, R., Ilišević, D., \& Ćurguz, N. B. (2019, November). Comparison of basic characteristics of 4G/LTE and 5G NR technology. In 2019 27th Telecommunications Forum (TELFOR) (pp. 1-4). IEEE.

[14]. Sertić, M. (2019). Analiza i Usporedba 5G Mreže S Tehnologijama Mobilnih Mreža Ranijih Generacija. (Doctoral dissertation, Josip Juraj Strossmayer University of Osijek. Faculty of Electrical Engineering, Computer Science and Information Technology Osijek. Department of Communications. Chair of Radiocommunications and Telecommunications).

[15]. Master LTE with the Help of an LTE Network Diagram (2014). Retrieved from: https://www.rcrwireless.com/20140509/evolvedpacket-core-epc/lte-network-diagram\#prettyPhoto [accessed: 16 July 2021].

[16]. Latha, D. H., Reddy, D. R. K., Sudha, K., Mubeen, A., \& Savita, T. S. (2014). A Study on 5th Generation Mobile Technology-Future Network Service. IJCSIT) International Journal of Computer Science and Information Technologies, 5(6), 8309-8313.

[17]. Akhtar, T., Tselios, C., \& Politis, I. (2021). Radio resource management: approaches and implementations from $4 \mathrm{G}$ to $5 \mathrm{G}$ and beyond. Wireless Networks, 27(1), 693-734.

[18]. Gupta, A., \& Jha, R. K. (2015). A survey of 5G network: Architecture and emerging technologies. IEEE access, 3, 1206-1232.

[19]. DeHon, A. (2015). Fundamental underpinnings of reconfigurable computing architectures. Proceedings of the IEEE, 103(3), 355-378.

[20]. Ezhilarasan, E., \& Dinakaran, M. (2017, February). A Review on mobile technologies: $3 \mathrm{G}, 4 \mathrm{G}$ and $5 \mathrm{G}$. In 2017 second international conference on recent trends and challenges in computational models (ICRTCCM) (pp. 369-373). IEEE.

[21]. Agiwal, M., Roy, A., \& Saxena, N. (2016). Next generation $5 \mathrm{G}$ wireless networks: A comprehensive survey. IEEE Communications Surveys \& Tutorials, 18(3), 1617-1655. 
[22]. Ngo, H. Q. (2015). Massive MIMO: Fundamentals and system designs (Vol. 1642). Linköping University Electronic Press.

[23]. Parikh, J., \& Basu, A. (2020). Technologies assisting the paradigm shift from $4 \mathrm{~g}$ to $5 \mathrm{~g}$. Wireless Personal Communications, 1-22.

[24]. Yousaf, F. Z., Bredel, M., Schaller, S., \& Schneider, F. (2017). NFV and SDN-Key technology enablers for $5 \mathrm{G}$ networks. IEEE Journal on Selected Areas in Communications, 35(11), 2468-2478.

[25]. Dan, Z., Cang, D., Zhou, H., Bai, H., \& Zong, Y. B. (2007). Preparation and Application of High Emissivity Coating on Regenerator of Hot Blast Stove for Energy Saving. Iron \& Steel, 42, 81-84.

[26]. Shin, S., Yegneswaran, V., Porras, P., \& Gu, G. (2013, November). Avant-guard: Scalable and vigilant switch flow management in software-defined networks. In Proceedings of the 2013 ACM SIGSAC conference on Computer \& communications security (pp. 413-424).

[27]. Maček, S. (2016). Razvoj i karakteristike mobilne mreže pete generacije (Doctoral dissertation, University of Zagreb. Faculty of Transport and Traffic Sciences. Division of Transport. Department of Information and Communications Traffic).

[28]. Ratasuk, R., Prasad, A., Li, Z., Ghosh, A., \& Uusitalo, M. A. (2015, February). Recent advancements in M2M communications in 4G networks and evolution towards 5G. In 2015 18th International Conference on Intelligence in Next Generation Networks (pp. 52-57). IEEE.
[29]. Čaušević, S., Medić, A., \& Branković, N. (2021). D2D Technology Implementation in 5G Network and the Security Aspect: A Review.

[30]. Militano, L., Araniti, G., Condoluci, M., Farris, I., \& Iera, A. (2015). Device-to-device communications for $5 \mathrm{G}$ internet of things. EAI Endorsed Transactions on Internet of Things, 1(1).

[31]. Livaja, I., \& Klarin, Z. (2020). Utjecaj 5G Mreže na Internet Stvari. Zbornik radova Veleučilišta $u$ Šibeniku, (1-2/2020), 155-169.

[32]. Al-Falahy, N., \& Alani, O. Y. (2019). Millimetre wave frequency band as a candidate spectrum for $5 \mathrm{G}$ network architecture: A survey. Physical Communication, 32, 120-144.

[33]. Cai, Y., Qin, Z., Cui, F., Li, G. Y., \& McCann, J. A. (2017). Modulation and multiple access for 5G networks. IEEE Communications Surveys \& Tutorials, 20(1), 629-646.

[34]. Liu, Y., Qin, Z., Elkashlan, M., Ding, Z., Nallanathan, A., \& Hanzo, L. (2017). Non-orthogonal multiple access for $5 \mathrm{G}$ and beyond. Proceedings of the IEEE, 105(12), 2347-2381.

[35]. Mei, L., Gou, J., Cai, Y., Cao, H., \& Liu, Y. (2021). Realtime Mobile Bandwidth and Handoff Predictions in $4 \mathrm{G} / 5 \mathrm{G} \quad$ Networks. arXiv preprint arXiv:2104.12959. 